\title{
Morphological control of zinc tricarbohydrazide perchlorate crystals: Theoretical and experimental study
}

\author{
LIU Rui, QI ShuYuan, ZHANG TongLai*, ZHOU ZunNing, YANG Li \& ZHANG JianGuo \\ State Key Laboratory of Explosion Science and Technology, Beijing Institute of Technology, Beijing 100081, China
}

Received October 5, 2012; accepted November 8, 2012; published online March 5, 2013

\begin{abstract}
The theoretical crystal-morphology of zinc tricarbohydrazide perchlorate $(\mathrm{ZnCP})$ was studied using the morphology simulation software. The growth trends and surface characteristics were calculated using the Bravais-Friedel-Donnay- Harker (BFDH), Growth Morphology, and Equilibrium Morphology methods; these provide theoretical guidance for the choice of crystal-control reagents. On the basis of the simulations, experiments were carried out to study the effects of five different crystal-control reagents, including carboxymethylcellulose (A), polyacrylamide (B), dextrin (C), Tween 40 (D), and Tween 60 (E), in the control of the crystal-morphology of $\mathrm{ZnCP}$. Mixtures of two reagents and higher temperatures were used to further optimize the $\mathrm{ZnCP}$ crystals. The results show that $\mathrm{ZnCP}$ crystals are well dispersed, and have a large apparent density and regular crystal-morphology under the control of a mixture of reagents $\mathrm{A}$ and $\mathrm{E}$ in a mass ratio of $1: 4$ at $80^{\circ} \mathrm{C}$.
\end{abstract}

physical chemistry, crystal-morphology, zinc tricarbohydrazide perchlorate $(\mathrm{ZnCP})$, crystal-control reagent, morphology simulation

Citation: $\quad$ Liu R, Qi S Y, Zhang T L, et al. Morphological control of zinc tricarbohydrazide perchlorate crystals: Theoretical and experimental study. Chin Sci Bull, 2013, 58: 1892-1896, doi: 10.1007/s11434-013-5683-8

The crystal-morphology of an energetic material has a direct effect on its physical properties such as fluidity, apparent density, electrostatic accumulation, and pressure resistance, and even has an important impact on its chemical and explosive properties such as stability, detonation ability, and sensitivity $[1,2]$. Generally, a material with a smooth surface, uniform particles, and spherical crystals has many advantages over needle- or twig-like irregular crystals, such as good fluidity, high apparent density (more than $0.8 \mathrm{~g} / \mathrm{cm}^{3}$ ), low sensitivity, and stable performance [3,4]. A fine crystal-morphology plays an important role in the safety and stability of a material [5-7]. Methods for controlling crystal-morphology can therefore be used to regulate nucleation and crystal growth during the crystallization process to increase the production and use of security of energetic materials, and improve their energy output performances [8-12].

Zinc tricarbohydrazide perchlorate $\left(\left[\mathrm{Zn}(\mathrm{CHZ})_{3}\right]\left(\mathrm{ClO}_{4}\right)_{2}\right.$, $\mathrm{ZnCP})$ is a new green energetic coordination compound that

*Corresponding author (email: ztlbit@bit.edu.cn) excludes toxic heavy metals [13]. However, ZnCP crystals prepared using traditional synthetic techniques are too small, fragmented, and irregular, and have poor fluidity and a small apparent density (less than $0.7 \mathrm{~g} / \mathrm{cm}^{3}$ ), leading to weak explosive power. Crystal-morphology control using a crystalcontrol reagent would improve the crystal quality, and enable $\mathrm{ZnCP}$ to be used as a green energetic material in practical applications.

In this study, the crystal-morphology and crystal-face parameters of $\mathrm{ZnCP}$ were simulated using the Morphology module of the Materials Studio simulation software (MS Morphology, Accelrys Corp., San Diego, CA, USA). Based on the theoretical calculations, experiments were performed to select the optimum crystal-control reagents and reaction conditions for the crystal-morphology optimization of $\mathrm{ZnCP}$.

\section{Theoretical study of crystal control}

\subsection{Morphology simulation}

The Morphology module [14] can simulate crystal-mor- 
phology using crystal-structure data. It calculates the stable crystal-morphology under different conditions, giving specific crystal-face parameters such as the surface area, attachment energy, surface energy, and relative growth rate. It analyzes the effect of the relative growth rate on the crystal-morphology, providing a theoretical basis for the choice of crystal-control reagent $[15,16]$.

The CIF file of the $\mathrm{ZnCP}$ crystal was imported into the MS Morphology software module and the crystal growth was simulated using three methods: the Bravais-FriedelDonnay-Harker (BFDH), Growth Morphology, and Equilibrium Morphology methods. The theoretical crystal-morphologies are shown in Figure 1.

Simulation using the BDFH method shows that the crystalmorphology of $\mathrm{ZnCP}$ is a square block shape with a length/diameter ratio of 1.71 . The crystal mainly consists of the (002), (10-1), (101), and (011) faces and their symmetrical crystal-faces. The simulated morphology obtained using the Growth Morphology method is a long block shape with a length/diameter ratio of 1.97 . It mainly consists of (002), (10-1), (101), and (011) faces and their symmetrical crystal-faces. Among them, the (002), (10-1), and (011) faces and their symmetrical crystal-faces occupy almost $90 \%$ of the total crystal-surface area. The morphology obtained using the Equilibrium Morphology method is an ellipsoid shape with a length/diameter ratio of 1.57 . It consists of (002), (10-1), (101), (011), (11-1), and (10-3) faces and their symmetrical faces. The main crystal-faces of $\mathrm{ZnCP}$ obtained using the three simulation methods are shown in Table 1. Taking these three models into consideration, the main crystal-faces, i.e. (002), (10-1), (101), and (011), were determined, and their structures are presented in Figure 2.

The common features of the (002), (10-1), (101), and (011) faces are the presence of an $\mathrm{O}$ atom (from $\mathrm{ClO}_{4}^{-}$) and an $\mathrm{N}$ atom (from the $\mathrm{CHZ}$ ligand) in or near the crystal surface, and strong intermolecular interactions. Suitable crystal-control reagents should therefore have functional groups containing active $\mathrm{H}$ atoms. The $\mathrm{H}$ atoms of the crystal-control reagent can form hydrogen bonds with the $\mathrm{O}$ atoms of the crystal-face, and change the relative growth rate of the crystal-face, achieving the purpose of crystal-morphology control.

\subsection{Selection of crystal-morphology-control reagent}

According to the Curie-Wulff principle [5], the vertical growth rate of the crystal-face is proportional to its surface tension. Surfactants, which are widely used as crystal-morphology-control reagents [17-20], can greatly reduce the surface tension, increase the diffusion coefficient of the solute and the viscosity of the reaction solution, and then reduce the rates of nucleation and crystal growth; these effects are conducive to primary explosive crystallization [21-25]. Based on the theoretical simulation results for $\mathrm{ZnCP}$, the control reagents should have active $\mathrm{H}$ atoms in their functional groups. In addition, high efficiency, simple and easy procurement, low cost, and good compatibility with $\mathrm{ZnCP}$ should also be considered. Carboxymethylcellulose (A), polyacrylamide (B), dextrin (C), Tween 40 (D), and Tween 60 (E) were therefore selected as control reagents. A is an ionic surfactant and $\mathrm{B}, \mathrm{C}, \mathrm{D}$, and $\mathrm{E}$ are non-ionic.

\section{Experimental}

\subsection{Materials}

$\mathrm{Zn}\left(\mathrm{ClO}_{4}\right)_{2}$ solution $(1 \mathrm{~mol} / \mathrm{L})$ was prepared by the reaction of $\mathrm{ZnO}$ (powder, $\mathrm{AR}$ ) and $\mathrm{HClO}_{4}$ (solution). $\mathrm{CHZ}$ solution ( $2 \mathrm{~mol} / \mathrm{L}$ ) was obtained by dissolving solid $\mathrm{CHZ}$ (powder, $\mathrm{AR}$ ) in deionized water. The crystal-morphology-control reagents $\mathrm{A}, \mathrm{B}, \mathrm{C}, \mathrm{D}$, and $\mathrm{E}$ (1 wt $\%$ ) were prepared using these solutions. All the raw materials were commercial products and used without further purification.

\subsection{Instruments}

DCAT-21-type surface/interfacial tension test device (Dataphysics Corp., Germany); the measurement range is 1-1000 $\mathrm{mN} / \mathrm{m}$ with an accuracy of $\pm 0.001 \mathrm{mN} / \mathrm{m}$. S-4800 coldfield-emission scanning electron microscope (SEM; Hitachi Corp., Japan); secondary electron detector, voltage $15 \mathrm{kV}$, resolution $1.0 \mathrm{~nm}$, zoom magnification $\times 30$ to $\times 80000$.

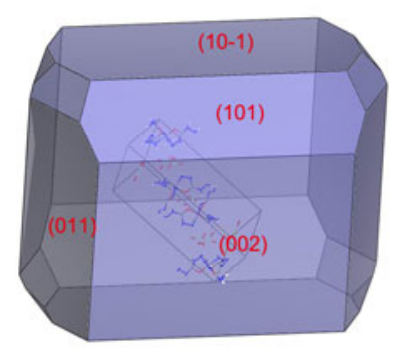

(a)

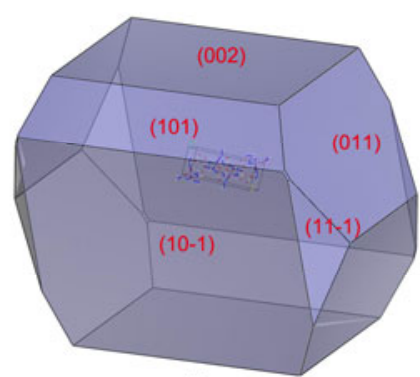

(b)

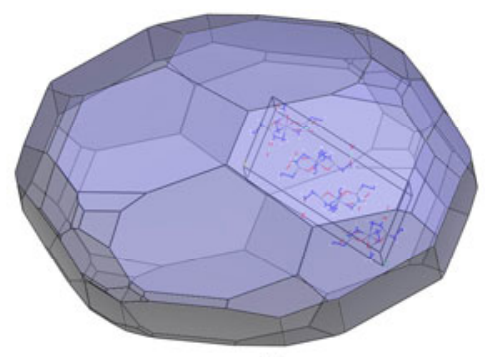

(c)

Figure 1 (Color online) ZnCP crystal-morphology simulated using BFDH method (a), Growth Morphology method (b), and Equilibrium Morphology method (c). 
Table 1 Proportions of main crystal-faces of $\mathrm{ZnCP}$ obtained using three simulation methods

\begin{tabular}{lccc}
\hline \multicolumn{1}{c}{ Crystal face } & $\begin{array}{c}\text { BFDH } \\
(\%)\end{array}$ & $\begin{array}{c}\text { Growth } \\
\text { Morphology }(\%)\end{array}$ & $\begin{array}{c}\text { Equilibrium } \\
\text { Morphology }(\%)\end{array}$ \\
\hline$(002)$ & 26.62 & 21.87 & 6.51 \\
$(10-1)$ & 26.04 & 34.32 & 10.59 \\
$(101)$ & 12.08 & 8.62 & 8.61 \\
$(011)$ & 30.79 & 30.55 & 16 \\
$(11-1)$ & - & - & 17.89 \\
$(10-3)$ & - & - & 7.06 \\
Total proportion & 95.53 & 95.36 & 66.66 \\
\hline
\end{tabular}

\section{Results and discussion}

\subsection{Characterization of crystal-control reagent}

The amount of crystal-control reagent for the optimum crystal-control effect is determined by the critical micelle concentration (CMC): the concentration of the crystal-control reagent should be slightly greater than the CMC. Solutions with different concentrations of crystal-control reagents were prepared at room temperature, and their surface tensions were measured. The curve of the dependence of the surface tension on concentration was plotted; the turning point of the curve represented the CMC. The results for crystal-control reagent $\mathrm{D}$ are shown in Figure 3; the CMC is 0.00786 mass\%. Using the same method, the $\mathrm{CMC}$ of $\mathrm{C}$ is 0.0623 mass\%, and that of $\mathrm{E}$ is 0.0135 mass\%. However, the viscosities of $\mathrm{A}$ and $\mathrm{B}$ are too large to accurately measure the surface tension, so the amounts of these are $0.1 \%$ to $0.3 \%$ of the total concentration.

\subsection{Effects of single crystal-control reagent}

The amount of the energetic material $\mathrm{ZnCP}$ synthesized was less than $10 \mathrm{~g}$, to ensure safety. First, $\mathrm{ZnCP}$ crystals were prepared by a traditional synthetic method without any crystalcontrol reagents. $\mathrm{Zn}\left(\mathrm{ClO}_{4}\right)_{2}$ solution was added dropwise to CHZ solution at $60^{\circ} \mathrm{C}$ in $30 \pm 5 \mathrm{~min}$, with a stirring speed of $250 \mathrm{r} / \mathrm{min}$ and a $\mathrm{pH}$ of 5 to 6 . After keeping at a constant temperature for $10 \mathrm{~min}, \mathrm{ZnCP}$ crystallized as the solution cooled down. The crystal-morphology without a control reagent is shown in Figure 4.

The crystals are irregular and have too many fragments. The crystal-morphology-control reagents were therefore added in different amounts in the synthetic process. All the morphologies were observed by SEM. The results are listed in Table 2. As an example, the crystal formed under the control of reagent $\mathrm{E}$ is shown in Figure 5.

The crystal-morphologies were improved by the crystalcontrol reagents. The shape is nearly regular and there are fewer fragments. Reagent A is an ionic surfactant, which

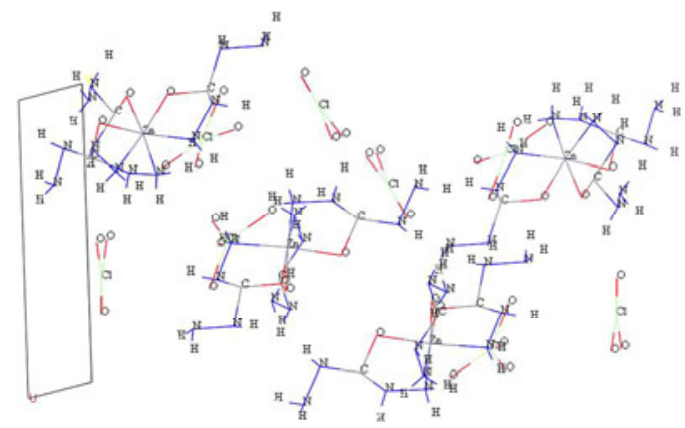

(a)

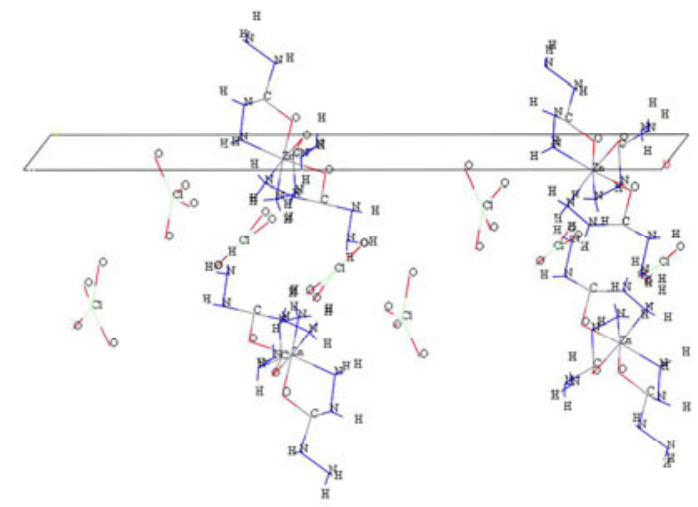

(c)

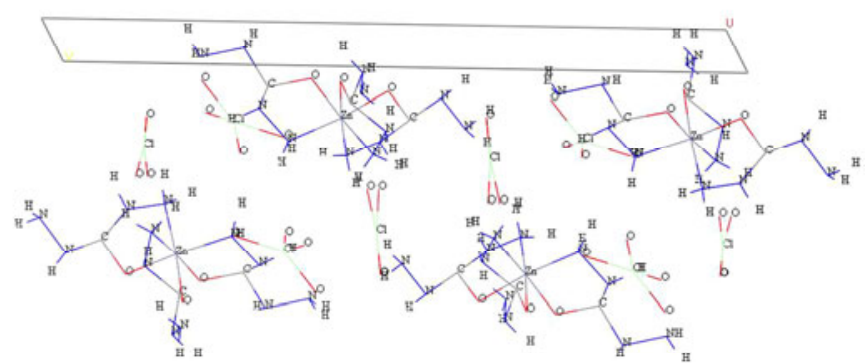

(b)

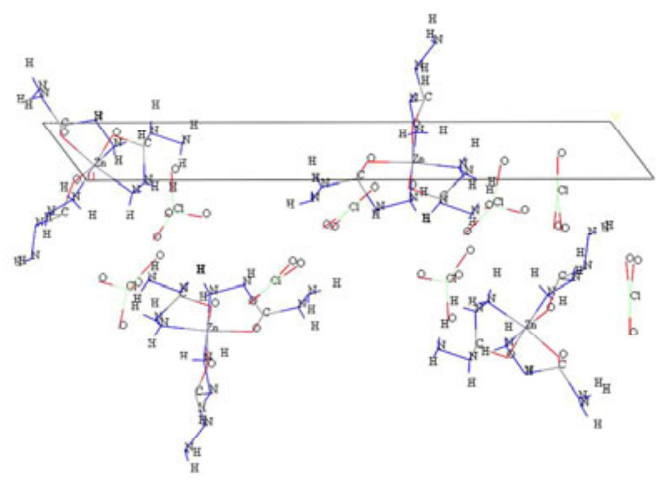

(d)

Figure 2 (Color online) Structures of crystal-faces of (002) (a), (10-1) (b), (101) (c), and (011) (d) for ZnCP. 


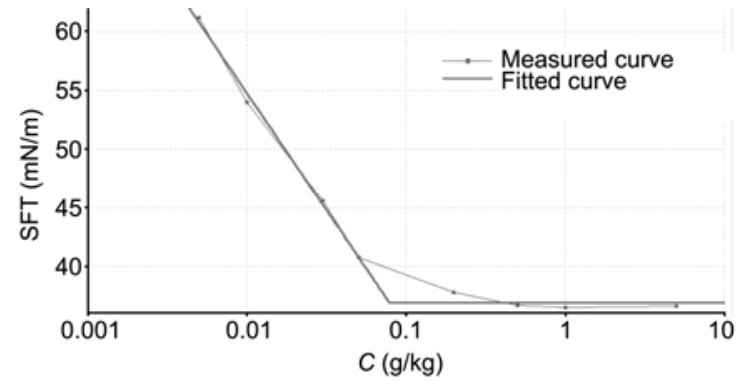

Figure 3 Relationship between concentration and surface tension for reagent $\mathrm{D}$.

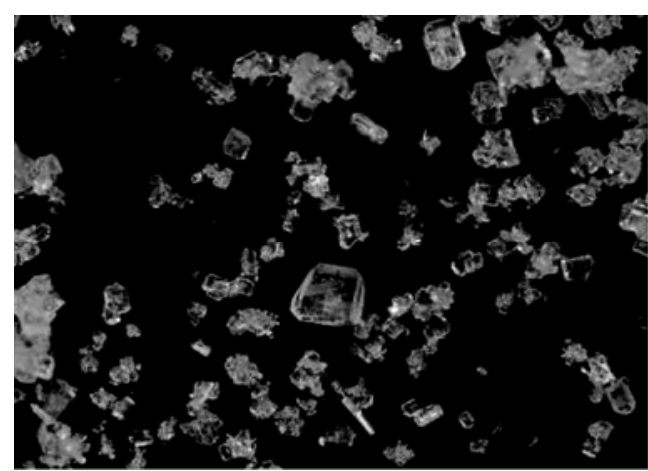

Figure 4 Crystal-morphology of $\mathrm{ZnCP}$ without crystal-control reagent.

Table 2 Crystal-morphologies of $\mathrm{ZnCP}$ obtained using different reagents

\begin{tabular}{ccccc}
\hline Reagent & $\begin{array}{c}\text { Amount } \\
(\mathrm{mL})\end{array}$ & $\begin{array}{c}\text { Yield } \\
(\%)\end{array}$ & $\begin{array}{c}\text { Apparent density } \\
\left(\mathrm{g} / \mathrm{cm}^{3}\right)\end{array}$ & Fluidity \\
\hline \multirow{3}{*}{$\mathrm{A}$} & 0.5 & 89.4 & 0.74 & Bad \\
& 1 & 90.7 & 0.71 & Bad \\
& 2 & 88.5 & 0.69 & Bad \\
\hline \multirow{3}{*}{ B } & 2 & 88.1 & 0.79 & Good \\
& 4 & 87.2 & 0.75 & Good \\
& 6 & 84.6 & 0.67 & Bad \\
\hline & 2 & 69.0 & 0.71 & Good \\
C & 4 & 80.1 & 0.73 & Good \\
& 8 & 88.6 & 0.67 & Bad \\
\hline & 1 & 83.0 & 0.75 & Bad \\
D & 2 & 85.1 & 0.65 & Bad \\
& 4 & 88.0 & 0.74 & Bad \\
\hline \multirow{2}{*}{ E } & 1 & 86.4 & 0.70 & Good \\
& 2 & 87.5 & 0.73 & Good \\
& 4 & 91.8 & 0.72 & Good \\
\hline
\end{tabular}

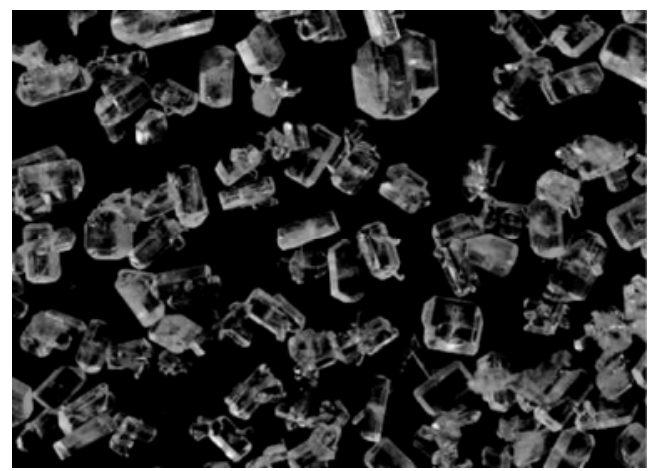

Figure 5 Crystal-morphology of $\mathrm{ZnCP}$ obtained using reagent $\mathrm{E}$. can form insoluble metal salts as nuclei for crystal growth. Reagents B, C, D, and E, as non-ionic surfactants, can greatly reduce the growth rate of the crystal-face to promote crystal growth, especially in the case of B, because of its high viscosity.

\subsection{Synergistic effects of multiple crystal-control reagents and temperature}

The effect of a single crystal-control reagent is very limited, and the obtained crystals have a non-uniform size and apparent density of less than $0.8 \mathrm{~g} / \mathrm{cm}^{3}$; these $\mathrm{ZnCP}$ crystals do not meet the requirements for industrial applications. The synergistic effects of multiple crystal-control reagents were therefore explored. Because of the different advantages of ionic and non-ionic crystal-control reagents, A was combined with the $\mathrm{B}, \mathrm{C}, \mathrm{D}$, and $\mathrm{E}$, respectively, in different ratios. It was found that the synergistic effect of $\mathrm{A}$ and $\mathrm{E}$ in a mass ratio of $1: 4$ is most effective: the morphology is more regular and the crystals are larger. The $\mathrm{ZnCP}$ crystal-morphology obtained using $\mathrm{A}$ and $\mathrm{E}$ is illustrated in Figure 6 . The compatibility of the crystal-control reagents and the reaction reagents should be considered, to avoid side effects. In this work, A, as an ionic surfactant, reacted with $\mathrm{Zn}\left(\mathrm{ClO}_{4}\right)_{2}$ to form an insoluble metal salts precipitate, and this should be avoided. Also, A and E cannot be mixed in large amounts, to avoid crystal bonding caused by high local concentrations of crystal-control reagents. Reagent A was therefore mixed with $\mathrm{CHZ}$, forming the base solution, and $\mathrm{E}$ and $\mathrm{Zn}\left(\mathrm{ClO}_{4}\right)_{2}$ were the added solution. When $\mathrm{Zn}\left(\mathrm{ClO}_{4}\right)_{2}$ solution was added to the $\mathrm{CHZ}$ solution, the two crystal-control reagents play a synergistic role in controlling the $\mathrm{ZnCP}$ crystals.

Although the $\mathrm{ZnCP}$ crystals were further improved by the synergistic action of multiple crystal-control reagents, the apparent density was still lower than $0.8 \mathrm{~g} / \mathrm{cm}^{3}$. The temperature is an important factor affecting the crystallization of primary explosives, so the reaction temperature was elevated from 60 to 70 and $80^{\circ} \mathrm{C}$, with the other conditions remaining unchanged.

The results show that $80^{\circ} \mathrm{C}$ is the most suitable temperature.

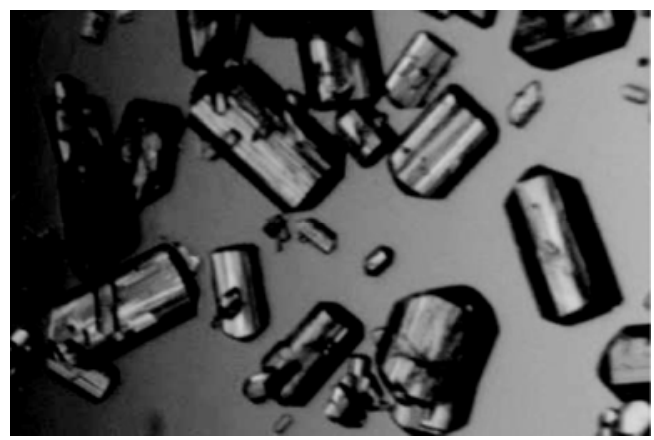

Figure 6 Crystal-morphology of $\mathrm{ZnCP}$ obtained using reagents A and $\mathrm{E}$ (1:4). 


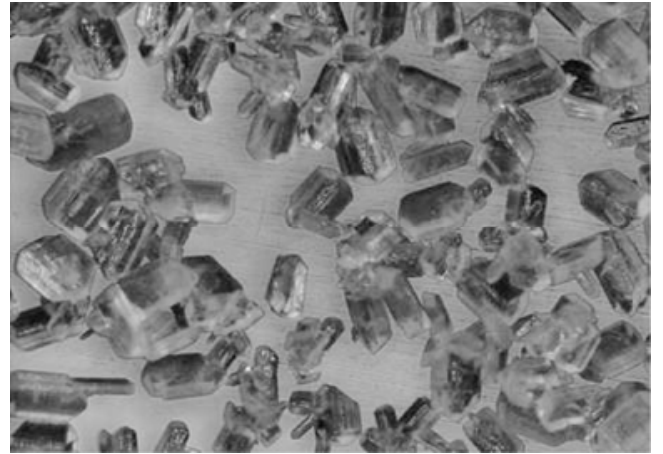

Figure 7 Crystal-morphology of $\mathrm{ZnCP}$ obtained using A and $\mathrm{E}(1: 4)$ at $80^{\circ} \mathrm{C}$.

The crystal-control reagents $\mathrm{A}$ and $\mathrm{E}$ mixed in a mass ratio of $1: 4$ at $80^{\circ} \mathrm{C}$ therefore gave the best performance, as shown in Figure 7, with a yield of $92.3 \%$, a neat morphology, good fluidity, and an apparent density of $0.86 \mathrm{~g} / \mathrm{cm}^{3}$.

\section{Conclusions}

The crystal-morphology of $\mathrm{ZnCP}$ was predicted using the Morphology simulation software, which analyzed the characteristics of the main crystal-faces using three simulation methods. Analog calculations provided theoretical guidance for the choice of the crystal-morphology-control reagents. The effects of reagents A, B, C, D, and E and the temperature on control of the crystal-morphology were investigated experimentally by SEM examination of the crystals. The results reveal that the synergistic effect of complex reagents is much more apparent than that of a single reagent. In particular, a complex reagent consisting of ionic surfactant $\mathrm{A}$ and non-ionic surfactant $\mathrm{E}$ in a mass ratio of $1: 4$ at $80^{\circ} \mathrm{C}$ regulated the crystals, to give a neat and regular morphology, good fluidity, a high yield, and a large apparent density. Good-quality crystals guarantee the usage security and performance stability of $\mathrm{ZnCP}$ as a primary explosive in practical applications.

This work was supported by the Science and Technology Fund on Applied Physical Chemistry Laboratory (9140C3703051105, 9140C370303120C37142), and the Key Support Foundation of State Key Laboratory of Explosion Science and Technology (QNKT12-02 and YBKT10-05).

1 Wang X Y, Li W M, Wang J L. Advance on the control technology of explosive crystal morphology (in Chinese). Shanxi Chem Ind, 2009, 1: 29-32

2 Zhang J G, Zhang T L, Yang L. Crystal control and single crystal culturing of the primary explosives (in Chinese). Initiators Pyrot, 2001, 1: 50-54

3 Li Y F, Zhang T L, Miao Y L, et al. New method of preparation of spherical KDNBF (in Chinese). Chinese J Explos Propell, 2003, 53-56

4 Jiang R G, Liu Z T. Study on prilling process of double salt $\mathrm{K} \cdot \mathrm{D}$ (II) primary explosive (in Chinese). Explos Mater, 2008, 21-23

5 Jiang R G, Liu Z T. Initiating Explosives (in Chinese). Beijing: Weapon Industry Press, 2006

6 Yang L, Ren X, Li T, et al. Preparation of ultrafine TATB and the technology for crystal morphology control. Chin J Chem, 2012, 30: 293-298

7 Feng J L, Zhang J G, Zhang T L, et al. Morphology control and its influence on the decomposition behavior and sensitivity of KDNBF. Acta Phys-Chim Sin, 2010, 10: 2613-2618

8 Liu X, Zhu B, Shao Y, et al. Control of morphology and structure of calcium carbonate crystals by heparin. Chin Sci Bull, 2010, 55: 1107-1111

9 Chen T, Shao M, Xu H, et al. Control over the crystal phase, crystallinity, morphology of $\mathrm{AgVO}_{3}$ via protein inducing process. J Colloid Interface Sci, 2012, 366: 80-87

10 Mou X, Li Y, Zhang B, et al. Crystal-phase- and morphology-controlled synthesis of $\mathrm{Fe}_{2} \mathrm{O}_{3}$ nanomaterials. Eur J Inorg Chem, 2012, 16: 2684-2690

11 Yamaguchi T, Ikuta K, Taruta S, et al. Morphology control and interlayer pillaring of swellable Na-taeniolite mica crystals. Mater Sci Eng B-Adv Funct Solid-State Mater, 2012, 177: 524-527

12 Zhang H, Sun J, Kang B, et al. Crystal morphology controlling of TATB by high temperature anti-solvent recrystallization. Propellants Explos Pyrotech, 2012, 37: 172-178

13 Qi S Y, Li Z M, Zhang T L, et al. Crystal structure, thermal analysis and sensitivity property of $\left[\mathrm{Zn}(\mathrm{CHZ})_{3}\right]\left(\mathrm{ClO}_{4}\right)_{2}$ (in Chinese). Acta Chim Sin, 2011, 8: 138-143

14 Ren X T, Yang L, Zhang G Y, et al. Computational simulation of the crystal morphology of TATB (in Chinese). Chin J Explos Propell, 2010, 43-46

15 Tang Z, Yang L, Qiao X J, et al. Calculated simulation of the crystal morphology of HMX (in Chinese). Chin J Explos Propell, 2009, $10-13$

16 Yang L, Ren X T, Yan Y J, et al. Crystal structure and morphology simulation of HNS (in Chinese). Chin J Explos Propell, 2009, 1-5

17 Krakhalev M N, Loiko V A, Zyryanov V Y. Electro-optical characteristics of polymer-dispersed liquid crystal film controlled by ionic-surfactant method. Tech Phys Lett, 2011, 37: 34-36

18 Luo Z, Li H, Xia J, et al. Controlled synthesis of different morphologies of $\mathrm{BaWO}_{4}$ crystals via a surfactant-assisted method. J Cryst Growth, 2007, 300: 523-529

19 Singh K, Mclachlan A A, Marangoni D G. Effect of morphology and concentration on capping ability of surfactant in shape controlled synthesis of PbS nano- and micro-crystals. Colloid Surf A-Physicochem Eng Asp, 2009, 345: 82-87

20 Wang F F, Li C S, Tang H. Morphological control of $\mathrm{PbWO}_{4}$ crystals in the ethanol-water mixed system with an anionic surfactant. J Alloy Compd, 2010, 490: 372-376

21 Bai H, Zhang W, Deng H, et al. Control of crystal morphology in poly ( $L$-lactide) by adding nucleating agent. Macromolecules, 2011, 44: 1233-1237

22 Chen Z, Nan Z. Controlling the polymorph and morphology of Ca$\mathrm{CO}_{3}$ crystals using surfactant mixtures. J Colloid Interface Sci, 2011, 358: 416-422

23 Dalvand P, Mohammadi M R, Fray D J. One-dimensional cadmium sulfide (CdS) nanostructures by the solvothermal process: Controlling crystal structure and morphology aided by different solvents. Mater Lett, 2011, 65: 1291-1294

24 Meng Z, Wei H Y. Effect of crystal modifier on crystal morphology of $\varepsilon$-HNIW (in Chinese). Chin J Energ Mater, 2011, 165-169

25 Chen H, Li L, Jin S, et al. Effects of additives on epsilonHNIWcrystal morphology and impact sensitivity. Propellants Explos Pyrotech, 2012, 37: 77-82

Open Access This article is distributed under the terms of the Creative Commons Attribution License which permits any use, distribution, and reproduction in any medium, provided the original author(s) and source are credited. 